\title{
Editorial
}

Int Neurourol J 2011;15:183

http://dx.doi.org/10.5213/inj.2011.15.4.183

pISSN 2093-4777 · eISSN 2093-6931

\section{Potential Use of Antiproliferative Factor as a Targeting Therapy in Painful Bladder Syndrome/Interstitial Cystitis}

\author{
Khae Hawn Kim \\ Associate Editor \\ Department of Urology, Gachon University of Medicine and Science, Incheon, Korea \\ E-mail: kimcho99@gilhospital.com
}

Painful bladder syndrome/interstitial cystitis (PBS/IC) encompasses a major portion of the "painful bladder" disease complex. "Painful bladder disorders" comprise a large group of patients with bladder and/or urethral and/or pelvic pain, irritative voiding symptoms (urgency, frequency, nocturia, and dysuria), and sterile urine cultures. Painful bladder conditions with well-established causes include radiation cystitis, cystitis caused by microorganisms that are not detected by routine culture methodologies, and systemic disorders that affect the bladder. In addition, many gynecologic disorders can mimic PBS/IC [1]. PBS/ IC has no easily discernible etiology. There are no pathognomonic findings on pathologic examination, and even the detection of petechial hemorrhages on the bladder mucosa during cystoscopy after bladder hydrodistention under anesthesia is no longer considered the sine qua non of PBS/IC that it had been until a decade ago [2]. PBS/IC is truly a diagnosis by exclusion. It may have multiple causes and represent a final common reaction of the bladder to different types of insult. There are numerous theories regarding its pathogenesis, but confirmatory evidence found in clinical practice has proven sparse. Among numerous proposals that have been further studied are leaky epithelium, mast cell activation, neurogenic inflammation, inhibition of uroepithelial cell proliferation: antiproliferative factor (APF), nitric oxide metabolism, urine abnormality and the role of genetics or some combination of these and other factors leading to a self-perpetuating process resulting in chronic bladder pain and voiding dysfunction [3]. Among the various possible evidences, APF has recently been the subject of much attention. The finding that cells from the bladder lining of normal controls grow significantly more rapidly in culture than cells from PBS/ IC patients led Keay et al. [4] at the University of Maryland to the discovery of an APF produced by the urothelium of IC patients. Studies are ongoing to confirm the hypotheses related to APF and expand on its significance in diagnosis and development of a rational targeting treatment approach. Especially, the article by Kim and Freeman [5] in this issue of the journal will be recognized as a valuable update on signal transduction pathways and networks that are responsive to APF to learning more about potential therapeutic pathways.

\section{REFERENCES}

1. Howard FM. Chronic pelvic pain. Obstet Gynecol 2003;101:594-611.

2. Erickson DR, Tomaszewski JE, Kunselman AR, Bentley CM, Peters KM, Rovner ES, et al. Do the National Institute of Diabetes and Digestive and Kidney Diseases cystoscopic criteria associate with other clinical and objective features of interstitial cystitis? J Urol 2005; 173:93-7.

3. Elbadawi A. Interstitial cystitis: a critique of current concepts with a new proposal for pathologic diagnosis and pathogenesis. Urology 1997;49(5A Suppl):14-40.

4. Keay S, Zhang CO, Trifillis AL, Hise MK, Hebel JR, Jacobs SC, et al. Decreased $3 \mathrm{H}$-thymidine incorporation by human bladder epithelial cells following exposure to urine from interstitial cystitis patients. J Urol 1996;156:2073-8.

5. Kim J, Freeman MR. Antiproliferative factor signaling and interstitial cystitis/painful bladder syndrome. Int Neurourol J 2011;15:18491.

This is an Open Access article distributed under the terms of the Creative Commons Attribution Non-Commercial License (http://creativecommons.org/licenses/by-nc/3.0/) which permits unrestricted non-commercial use, distribution, and reproduction in any medium, provided the original work is properly cited. 